\title{
Impactos e consequências das dietas da moda e da suplementação no comportamento
}

\section{alimentar}

\author{
Impacts and consequences of fad diets and supplementation on eating behavior \\ Impactos y consecuencias de las dietas de moda y la suplementación en la conducta alimentaria
}

Recebido: 04/08/2021 | Revisado: 09/08/2021 | Aceito: 11/08/2021 | Publicado: 15/08/2021

\author{
Alceu Luiz Faria \\ ORCID: https://orcid.org/0000-0001-6499-4276 \\ Centro Universitário de Brasília, Brasil \\ E-mail: alceu.faria@sempreceub.com \\ Simone Gonçalves de Almeida \\ ORCID: https://orcid.org/0000-0001-5839-3052 \\ Centro Universitário de Brasília, Brasil \\ E-mail: simone.almeida@ceub.edu.br \\ Theo Moraes Ramos \\ ORCID: https://orcid.org/0000-0001-6742-5757 \\ Centro Universitário de Brasília, Brasil \\ E-mail: theoxpto@gmail.com
}

\begin{abstract}
Resumo
As dietas da moda vem ganhando cada vez mais evidência nas mídias e redes sociais sendo tratadas como "dietas milagrosas" prometendo resultados imediatos para fins estéticos em um curto período. O objetivo do presente trabalho é discutir os impactos e consequências das dietas restritivas e suplementos que são utilizados sem a prescrição de um profissional habilitado. Esse trabalho trata-se de uma revisão bibliográfica, onde foram acessadas as seguintes bases de dados: Pubmed, Google Acadêmico e SciELO. Os artigos selecionados foram em sua maioria posteriores a 2010, porém foi necessária a busca por pesquisas realizadas anteriormente a 2010, devido à ausência de uma base de dados concreta. A importância da orientação adequada de um profissional nutricionista em relação ao plano alimentar de um paciente é primordial para evitar prejuízos à saúde mental e física ocasionadas por restrições alimentares. Destaca-se também o uso correto de suplementos alimentares prescritos por um profissional nutricionista e a individualidade de cada um deles para o organismo de cada paciente, e assim evitando prejudicar a saúde com o uso incorreto.
\end{abstract}

Palavras-chave: Dietas da moda; Transtornos da alimentação e da ingestão de alimentos; Ciências da nutrição.

\begin{abstract}
Fad diets are gaining more and more evidence in the media and social networks being treated as "miracle diets" promising immediate results for aesthetic purposes in a short period. The objective of this work is to discuss the impacts and consequences of restrictive diets and supplements that are used without the prescription of a qualified professional. This work is a bibliographic review, where the following databases were accessed: Pubmed, Academic Google and SciELO. The selected articles were mostly after 2010, but it was necessary to search for research carried out before 2010, due to the absence of a concrete database. The importance of proper guidance from a professional nutritionist in relation to a patient's eating plan is essential to avoid damage to mental and physical health caused by dietary restrictions. Also noteworthy is the correct use of dietary supplements prescribed by a professional nutritionist and the individuality of each one for the body of each patient, thus avoiding harming health with incorrect use.
\end{abstract}

Keywords: Fad diets; Feeding and eating disorders; Nutritional sciences.

\section{Resumen}

Las dietas de moda están ganando cada vez más evidencia en los medios y redes sociales siendo tratadas como "dietas milagrosas" que prometen resultados inmediatos con fines estéticos en un corto período. El objetivo de este trabajo es discutir los impactos y consecuencias de las dietas restrictivas y los suplementos que se utilizan sin la prescripción de un profesional calificado. Este trabajo es una revisión bibliográfica, donde se accedió a las siguientes bases de datos: Pubmed, 
Academic Google y SciELO. Los artículos seleccionados fueron en su mayoría posteriores a 2010, pero fue necesario buscar investigaciones realizadas antes de 2010, debido a la ausencia de una base de datos concreta. La importancia de la orientación adecuada de un nutricionista profesional en relación con el plan de alimentación del paciente es fundamental para evitar daños a la salud física y mental causados por las restricciones dietéticas. También cabe destacar el correcto uso de los complementos dietéticos prescritos por un nutricionista profesional y la individualidad de cada uno para el organismo de cada paciente, evitando así dañar la salud con un uso incorrecto.

Palabras clave: Dieta de moda; Trastornos de alimentación y de la ingestión de alimentos; Ciencias de la nutrición.

\section{Introdução}

A tentativa com resultados imediatos em relação ao emagrecimento para fins estéticos aumenta significativamente a cada ano. As dietas da moda, por sua vez, prometem ajudar na redução de peso e ganho de massa muscular com rapidez e acabam aparentando ser a melhor opção para as pessoas que buscam esse objetivo. Essas dietas são consideradas não saudáveis, pois fornecem menos calorias e nutrientes e seu sucesso é limitado a longo prazo (Soihet \& Silva, 2019).

De acordo com o Guia alimentar para a população brasileira a alimentação saudável e adequada é um direito básico que engloba o acesso regular, de forma socialmente justa, à uma alimentação adequada aos princípios biológicos e sociais do indivíduo e de acordo com as necessidades alimentares, engloba a cultura alimentar e as questões de gênero, raça e etnia, é acessível do ponto de vista físico e financeiro, possui harmonia no que tange a quantidade e qualidade, atendendo aos princípios da variedade, equilíbrio, moderação e prazer; e baseada em práticas produtivas adequadas e sustentáveis. Pedro Escudero, conhecido como um dos pioneiros no estudo da nutrição, firmou quatro leis que regem uma alimentação saudável, sendo elas: lei da quantidade, lei da qualidade, lei da harmonia e lei da adequação (Marangoni et al., 2017).

As dietas restritivas, também conhecidas popularmente como dietas da moda, vêm ficando em evidência nas últimas décadas por conta de celebridades, que adquirem um poder de influência através das mídias e as prescrevem sem informações científicas, intitulando-as como "dietas milagrosas", prometendo resultados mirabolantes (Soihet \& Silva, 2019).

As redes sociais passaram a ser um meio de transmissão de informações bastante amplo, com vários influenciadores que, com o seu grande poder midiático, postam seu estilo de vida e acabam tornando seus hábitos desejados pelos seguidores que os acompanham. Os nutricionistas vêm se inserindo nas mídias sociais de diversas maneiras em consequência da globalização e da transição nutricional, pois as pessoas constantemente buscam resultados e informações acessíveis, gratuitas e rápidas, o que abre espaço para conteúdos postados nas redes sociais (Fraga et al., 2018).

De acordo com o Código de Ética e de Conduta do Nutricionista é dever do nutricionista adequar condutas e práticas profissionais às necessidades dos indivíduos, coletividades e serviços de forma que promova a saúde sem ceder a modismos, pressões mercadológicas ou midiáticas e a interesses financeiros, assim como analisar criticamente questões técnicas e metodológicas de práticas, pesquisas e protocolos divulgados na literatura ou adotados por instituições e serviços, bem como a própria conduta profissional. O nutricionista deve ter como objetivo principal a promoção da saúde e a educação alimentar e nutricional, de forma crítica e com respaldo científico ao compartilhar informações sobre alimentação e nutrição nos diversos meios de comunicação e informação.

A mídia idealiza um corpo perfeito gerando uma pressão para que o indivíduo se encaixe nesse molde, aderindo às dietas restritivas para alcançar uma redução de peso significativa em curto prazo. Indivíduos que vivem a alternância constante entre essas dietas restritivas tendem a ser mais propícios a obsessões alimentares, episódios de compulsão alimentar e transtornos relacionados à alimentação, pois desenvolveram hábitos como a preocupação excessiva com as calorias ingeridas. Além disso, muitas vezes sofrem as consequências de uma dieta com baixo aporte nutricional como maior irritabilidade, dificuldade de concentração, fadiga, intolerância ao frio, nervosismo, euforia, cefaleia. 
Junto com o crescimento da adesão a dietas restritivas, cada vez cresce mais a utilização de suplementos alimentares a fim de uma melhora na performance, redução do peso ou ganho de massa. O uso desses produtos está se tornando um hábito na vida de praticantes de atividade física, pessoas que querem resultados rápidos em pouco tempo, para fins estéticos, com objetivo de ganhar massa muscular e emagrecer. (Carvalho et al., 2018).

Os suplementos são compostos por minerais, vitaminas e outras substâncias que são formulados para complementar a necessidade de um indivíduo em caso de um desequilíbrio nutricional na dieta tradicional, para atender as condições metabólicas e fisiológicas individualizadas (Gomes et al., 2017 \& Silva \& Souza, 2016). Devido ao fácil acesso desses suplementos alimentares nos comércios, pois essas mercadorias não precisam de receita médica para serem adquiridos, consumidores de qualquer tipo podem realizar a compra desses produtos (Fernandes \& Machado, 2016). Muitas dessas vendas simplificadas dessas substâncias se dão por conta da influência das mídias e redes sociais (Molin et al., 2019).

Os transtornos alimentares têm como características serem distúrbios mentais relacionados ao comportamento dos hábitos alimentares e controle da massa corporal, que podem resultar na convivência social e afetar a saúde física e psicológica. Algumas atitudes das pessoas que possuem essas enfermidades são a exclusão de certos grupos alimentares, julgando-os calóricos demais; permanência em jejum durante longos períodos do dia; tendência em tomar medidas compensatórias inadequadas (vômitos induzidos, uso de laxantes, inibidores de apetite, diuréticos) para que seu aspecto corporal não mude, podendo trazer consequências graves e até ameaçar a vida (Mcardle et al., 2011).

As dietas da moda geram um grande impacto no perfil comportamental de indivíduos que fazem adesão a elas, acreditando no seu "potencial milagroso" de redução drástica e veloz de peso. Cada vez mais pessoas adotam dietas da moda devido à influência das mídias, principalmente das redes sociais, que atualmente dão muito poder de persuasão para influenciadores que muitas vezes não têm nenhum conhecimento técnico, o que em uma área da saúde como a Nutrição é completamente negativo para a sociedade. A alternância constante entre dietas restritivas e sem base científica, como são as dietas da moda, é um fator precursor para o desenvolvimento de hábitos característicos de transtornos alimentares (Lima et al., 2015).

Muitas vezes as dietas da moda são criadas a partir de estudos sem validade nenhuma. De acordo com Lima et al. (2015), as dietas da moda costumam ser chamadas dessa maneira por serem práticas alimentares amplamente conhecidas e temporárias, que prometem resultados rápidos e atrativos, mas carecem de embasamento científico. Outro fator que compromete a efetividade das dietas da moda é a sua falta de personalização e de individualidade, sendo um plano alimentar prescrito sem nenhuma avaliação ou anamnese do paciente. Suas taxas metabólicas basais não são calculadas individualmente e os hábitos alimentares do paciente não são observados para a prescrição dessas dietas. A prescrição de um plano alimentar, como todas as atividades envolvidas na atuação de um profissional nutricionista, devem ser orientadas a partir de um embasamento teórico-científico.

A necessidade desse estudo se justifica pois as dietas da moda geram um grande impacto no perfil comportamental de indivíduos que fazem adesão a elas. Tendo como referência o assunto proposto, o presente estudo tem como objetivo discutir acerca do impacto que as dietas da moda, que não trazem fundamentos científicos, causam no comportamento alimentar e nutricional. Assim como realizar a análise das influências das dietas de caráter restritivo nos hábitos alimentares de cada indivíduo e identificar os principais meios de comunicação responsáveis por divulgar as dietas da moda. Dessa forma é possível analisar a relação existente entre a adesão a essas dietas e distúrbios do comportamento alimentar.

\section{Metodologia}

Foi realizada revisão bibliográfica de natureza qualitativa através de artigos e literaturas relacionados às dietas da moda e aos transtornos alimentares e seus impactos na nutrição comportamental. O estudo tem como público alvo adolescentes de a partir dos 16 anos e adultos de até 30 anos que sofrem ou já sofreram algum tipo de distúrbio alimentar. 
O trabalho de pesquisa foi realizado utilizando os seguintes bancos de dados: PubMed, Google Acadêmico e SciELO. Os idiomas da pesquisa são o Inglês, Português e Espanhol, por meio de descritores como "Dietas da moda", "Transtornos alimentares", "Nutrição Comportamental", "Fad diets", "Eating disorders", "Behavioral Nutrition", "Dieta de Moda", "Trastornos de la Alimentación", "Nutrición Conductual". Para o desenvolvimento do levantamento de dados foram utilizados artigos originais e de revisão, além de livros, que possuem foco em discutir os impactos no comportamento alimentar recorrentes de dietas restritivas.

Os artigos foram selecionados por meio de estratégias de busca dos descritores previamente comunicados nos bancos de dados PubMed, Google Acadêmico e SciELO. Na presente pesquisa foram utilizados artigos de revisão, estudos prospectivos, estudos de caso-controle e estudos de coorte.

Os artigos analisados foram definidos através da leitura dos resumos e títulos dos artigos prospectados e, caso se encontrassem dentro do corpus do estudo, sua leitura foi realizada na íntegra. Os critérios de exclusão foram artigos que apresentassem anos anteriores a 2010, não se relacionassem ao público alvo e que não estivessem alinhados ao escopo do estudo.

Devido à ausência de uma base de dados consolidada acerca do assunto, foi necessária a busca de algumas pesquisas realizadas anteriormente a 2010, no intuito de uma melhor compreensão.

Os artigos foram previamente selecionados e submetidos ao método de amostragem não probabilística snowball. O método de amostragem não probabilística snowball reúne uma amostragem em cadeia e não probabilística, em que os artigos de estudo prospectados recrutam artigos futuros. Essa metodologia aplicada ao presente estudo consistiu na busca por referências e citações, que se encaixavam nos critérios de inclusão previamente definidos, nos estudos já prospectados e caso se encaixem, foram então incluídos no material de análise.

\section{Resultados e Discussão}

\section{Redes sociais}

Devido ao crescente intuito de melhorar a aparência, emagrecer, controlar a obesidade, um variado espectro de dietas que prometem resultados rápidos tem surgido. As dietas da moda podem ser definidas como padrões de comportamento alimentar adotados entusiasmadamente por seus adeptos, e podem ser intituladas dessa maneira por serem populares e efêmeras, promovendo resultados rápidos e que parecem interessantes, porém carecem de embasamento científico (Lima et al.,2015).

A busca por um determinado padrão de corpo não é algo novo. A percepção que temos do corpo muda ao longo do tempo, e cada período da história e cultura têm sua obsessão com um padrão corporal específico, principalmente com a imagem do corpo feminino, intrinsecamente ligado a um ideal de beleza imposto pela mídia (Sousa et al., 2018). A preocupação atual com a aparência, com a perda e controle de peso gera a busca por dietas na imprensa popular, mídias sociais, blogs.

Nas últimas décadas os meios de comunicação são veículos que estabelecem hábitos e práticas alimentares com base em determinações socioculturais, concebendo a maior forma de propagação destes pensamentos e imposição de valores alimentares distorcidos da realidade (Magalhães, 2017). Há um constante aumento na utilização das mídias sociais como forma de se adquirir conhecimento acerca de alimentação, nutrição e saúde.

Nas redes sociais frequentemente ocorre a divulgação e promoção de padrões alimentares e dietas populares, direcionadas para a população em geral e não a grupos específicos, como recomendam consensos nutricionais nacionais e internacionais (Peixoto, 2020). Ocorre um desfalque de páginas dedicadas à promoção de padrões alimentares baseadas em evidências científicas, e as existentes não conseguem atingir a população em geral.

Uma dieta individualizada e adequada deve ser planejada de acordo a exclusividade de cada paciente e ser variada contendo todos os grupos alimentares promovendo frequentemente bons hábitos alimentares. Segundo Mahan (2010) para uma perda saudável 
de $0,45 \mathrm{~kg}$ a $1 \mathrm{~kg}$ por semana, o déficit diário não pode ultrapassar de $500 \mathrm{kcal}$ a $1.000 \mathrm{kcal}$, e pode ser mantida até seis meses. Considera-se uma dieta restritiva e prejudicial ao corpo qualquer dieta com valor energético inferior a $800 \mathrm{kcal} / \mathrm{dia}$.

De acordo com o Conselho Federal de Nutricionistas, capítulo 4, artigo 58, É vedado ao nutricionista, mesmo com autorização concedida por escrito, divulgar imagem corporal de si ou de terceiros, atribuindo resultados a produtos, equipamentos, técnicas, protocolos, pois podem não apresentar o mesmo resultado para todos e oferecer risco à saúde.

No estudo de Lira et al. (2017), feito com adolescentes do sexo feminino estudantes de escola pública e de uma organização não governamental da capital e do interior de São Paulo, foi analisada a possível relação de influência que as redes sociais exercem sobre a autoimagem corporal das jovens. O estudo concluiu que ocorre influência das mídias sobre a autoimagem corporal das adolescentes que compunham a amostra do estudo, principalmente quando há uma internalização da opinião da mídia pelas jovens, e sugeriu que fossem feitos novos estudos acerca do assunto para se criar um maior embasamento no escopo desse tema.

Magalhães et al. (2017) desenvolveram um estudo em que foi aplicado um questionário para alunos de ambos os gêneros regularmente matriculados em escolas de ensino médio, ensino superior e academias que perguntavam acerca do consumo de conteúdos que abordam alimentação dentro das redes sociais. O estudo traz a reflexão que as redes sociais se tornaram uma grande loja onde empresas investem em blogueiras no intuito de que elas levem seus produtos ao maior número de consumidores possíveis, porque passam a imagem de serem pessoas comuns e conquistam a confiança de seus seguidores. $\mathrm{O}$ estudo concluiu que, mesmo com os participantes conectados a várias redes sociais, a maioria não segue uma blogueira "fitness", e muitos dos que seguem não são influenciados por suas opiniões, independente se de alimentação, moda ou atividade física.

Em um mundo onde cada vez mais a mídia desenvolve uma função importante de geração de opinião, cabe ao profissional nutricionista estar ciente da dimensão e do teor das informações que se passam na mídia e qual a sua influência sobre os hábitos alimentares da população (Magalhães et al., 2017).

\section{Dietas da Moda}

De acordo com Betoni et al. (2010) as Dietas da Moda são dietas que alguns indivíduos aderem e são práticas temporárias, populares, que prometem resultados rápidos, mas carecem de maiores embasamentos científicos. Atualmente, cada dia cresce mais a exposição de dietas, cardápios semanais, e depoimentos de pessoas que emagreceram, indicando meios para se conseguir o emagrecimento (Nogueira et al., 2016).

O artigo de Nogueira et al. (2016) apresenta como as principais dietas da moda a Dieta Atkins, Dieta do tipo sanguíneo, Dieta da sopa, Dieta da Lua, Método Dukan e Dieta detox. Esse estudo traz que essas mostra dietas são ineficazes a longo prazo, pois apenas $15,4 \%$ dos participantes do estudo mantiveram o peso perdido por tempo posterior a um ano, mas mesmo assim a maioria dos participantes classifica o resultado da dieta como muito bom, indicando possivelmente que os resultados a curto prazo sejam suficientes para o público alvo do estudo.

As dietas divulgadas nas redes sociais podem ser prejudiciais ao organismo de certas pessoas. Foram apresentadas através do "Google trends" as dietas da moda (cetogênica, da lua, da proteína, da sopa, detox, dos pontos, paleo e Dukan) que mais tiveram acesso, quando pesquisadas pelo termo "dieta", nas plataformas. Esses planos alimentares são conhecidos por prometerem causar mudanças rápidas em um curto período e transformar seu corpo semelhante ao do seu influenciador preferido, celebridades e modelos (Passos et al., 2020)

Segundo o artigo de Ana Cláudia et al. (2017), algumas das dietas popularizadas citada pela revista, temos como exemplo as dietas de desintoxicação, conhecidas por ajudar a tirar as impurezas do corpo, as toxinas ambientais e por colaborar na perda de peso. Já as dietas de baixo volume calórico são planos alimentares que até podem ser feitos em um curto período e com 
acompanhamento de um médico. No entanto, se realizadas sem um profissional da área, podem trazer várias complicações à saúde e até a recuperação do peso após a dieta (Freire et al., 2017).

Dietas low carbs também foram globalizadas promovendo o consumo desbalanceado de macronutrientes, diminuindo a ingestão de carboidratos e aumentando a ingestão de proteínas e gorduras em quantidades consideradas não saudáveis. As pesquisas que avaliaram esse tipo de dieta foram consideradas pelos avaliadores com resultados mistos. Uns acreditam que esse plano alimentar permite a redução de peso mas também o seu ganho, e outros acreditam que há uma redução de água e não de peso, porém, uma revisão sistemática descobriu que não há evidências que a redução do carboidrato gera o emagrecimento (Freire et al., 2017).

O artigo de Marangoni et al. (2017) que analisou 24 cardápios publicados em três revistas distintas nos meses de novembro e dezembro de 2015 e janeiro e fevereiro de 2016 concluiu que esses cardápios não atingem a maior parte das necessidades nutricionais e não levam em consideração a individualidade biológica, o que pode representar risco às pessoas que os seguem. Esse estudo trouxe que dentro das dietas da moda analisadas os valores de proteínas se encontravam dentro da faixa de recomendação nutricional e os valores de carboidratos se encontravam abaixo do limite mínimo em 5 dos cardápios analisados (Marangoni et al., 2017).

De acordo com a recomendação nutricional essas dietas restritivas são caracterizadas por serem generalizadas e não calculadas de acordo com os hábitos alimentares, tipos de atividades físicas e doenças dos indivíduos. Em um estudo realizado por Betoni et al. (2010), que coletou dados de pacientes que já haviam realizado dietas da moda, foi verificado que $45,45 \%$ dos pacientes que adotaram esse tipo de dieta acreditam que o resultado da dieta realizada foi muito ruim, 27,27\% acreditam que o resultado da dieta foi ruim, 18,18\% acreditam que foi bom e 9,09\% que foi muito bom. No que diz respeito ao tempo que os pacientes se mantiveram com os objetivos esperados, 36,36\% afirmam que o tempo foi muito curto, 36,36\% acreditam que o tempo foi curto, 9,09\% acreditam que o tempo foi longo e 9,09\% que foi muito longo (Betoni et al., 2010).

Quanto aos sintomas relatados pelos pacientes enquanto eram adeptos a essas dietas 63,63\% deles relataram sentir fraqueza, $54,54 \%$ relataram irritabilidade, 54,54\% relataram tontura, 36,36\% dor de cabeça, 27,27\% perda de cabelo, 9,09\% unhas fracas, 9,09\% anemia, 9,09\% desmaio. Muitos desses sintomas se devem ao fato de essas dietas não terem um aporte calórico adequado individualizado de acordo com o paciente (Betoni et al., 2010).

Muitas vezes esses sintomas relatados ocorrem devido a um baixo aporte calórico e nutricional. De acordo com um estudo de Pacheco et al. (2009) envolvendo dietas publicadas em revistas não científicas, o valor calórico médio dessas dietas é de aproximadamente 710 a 1328 calorias. Segundo os autores desse estudo, uma dieta com valor calórico inferior a 1200 Kcal é insuficiente. Além disso, em dietas de revistas não científicas a Taxa Metabólica Basal não é calculada individualmente, o que acarreta o não atendimento das necessidades energéticas dos pacientes, podendo gerar problemas de saúde (Pacheco et al., 2009).

\section{Dietas da Moda x Transtornos alimentares.}

O comportamento alimentar é muito mais que o ato de comer, engloba estímulos internos e externos, fatores orgânicos, psicológicos e sociais, possui motivações ocultas relacionadas às carências psicológicas e às emoções e conflitos que não dependem somente da fome e das necessidades fisiológicas (Soihet \& Silva, 2019).

Os transtornos alimentares são fenômenos multifatoriais resultantes da interação de fatores pessoais, familiares e socioculturais, e se caracterizam pela preocupação intensa com alimentação, peso e aparência. Os tipos de transtornos alimentares são: anorexia nervosa, bulimia nervosa e transtornos alimentares não especificados, como o transtorno do comer compulsivo. De acordo com American Psychiatric Association, a prevalência de anorexia nervosa seria por cerca de 0,3 a 3,7\% e a prevalência de bulimia nervosa por cerca de 1,1 a $4 \%$ na população jovem feminina, enquanto a população masculina representa apenas $10 \%$ do total de casos de transtornos alimentares (Magalhães \& Mendonça, 2005). 
As principais complicações clínicas geradas pelos transtornos alimentares são hipoglicemia, alterações endócrinas, hipercolesterolemia, queda da densidade mineral óssea, hipotensão, alterações pulmonares, arritmia cardíaca devida às perdas hidroeletrolíticas, insuficiência renal e até possível suicídio (Penz et al., 2008).

Os transtornos alimentares são divididos em duas categorias principais: anorexia nervosa e bulimia nervosa. Apesar de serem classificados separadamente, os dois transtornos são intrinsecamente relacionados por apresentarem psicopatologia comum, um transtorno que envolve a preocupação excessiva com o peso e a autoimagem, que leva os pacientes a aderirem dietas extremamente restritivas ou a utilizarem métodos inapropriados para alcançarem o corpo idealizado. Os pacientes que possuem esses transtornos exercem um autojulgamento com um peso excessivo na imagem corporal. (Penz et al., 2008)

De acordo com o estudo citado acima, também são fatores que podem influenciar o surgimento de transtornos alimentares a percepção da autoimagem corporal, refletida como uma insatisfação da própria imagem corporal; a influência de amigos e familiares; o uso de dieta restritiva, que, quanto maior a frequência, mais indica a preocupação excessiva com o peso corporal; a prática excessiva de atividade física; e o consumo de conteúdo que exalta a adesão à dieta restritiva e a magreza como símbolo de beleza, poder e sucesso.

A busca por um corpo perfeito, com restrição e controle alimentar severos, é o fator mais significativo e altamente sensível, na questão da capacidade de ser um fator prévio e confirmar um quadro de anorexia e/ou bulimia nervosas. Outro aspecto significativo é a alta motivação para alcançar uma magreza além da esperada, existindo uma discrepância entre o peso real e suas expectativas. Existem diversos estudos que relacionam a prática de dietas com o desenvolvimento de transtornos alimentares (Soihet \& Silva, 2019).

De acordo com o artigo científico de Morgan, Vecchiatti e Negrão (2002) a dieta de emagrecimento é o fator precipitante mais frequente nos transtornos alimentares. Progressivamente estudos longitudinais mostram que a dieta aumenta de modo considerável o risco para os transtornos alimentares. Indivíduos que fazem dieta apresentaram um risco 18 vezes maior para o desenvolvimento de transtornos alimentares do que entre indivíduos que não faziam dieta depois de um ano de continuidade. $\mathrm{O}$ estudo afirma que a restrição calórica, por si só, não é capaz de gerar o transtorno, mas, acompanhada de certos fatores de risco, colabora com esse desfecho.

Como explicita o artigo de Andrade et al., (2021), as dietas restritivas geram desequilíbrios hormonais afetando a função da regulação do balanço energético causando diversas desordens no organismo, ansiedade, nervosismo, obsessão por comida, diminuição da saciedade, aumento da fome, angústia e culpa, depressão, e perda de controle na ingestão alimentar. Os transtornos e compulsões alimentares estão ligados a práticas de alimentação auto impostas e preocupações descompensadas com o peso corporal.

$\mathrm{O}$ estudo traz a reflexão acerca de que dietas com restrição alimentar produzem danos à saúde mental do paciente e desencadeiam prejuízos na alimentação e nutrição do organismo, criando comportamentos compulsivos como um mecanismo de compensação ao sofrimento causado pela restrição alimentar e, posteriormente, podem gerar o desenvolvimento de compulsão alimentar.

O artigo de Andrade et al., (2021) afirma que o transtorno de compulsão alimentar surge através de algumas perturbações do comportamento alimentar como restrições alimentares, dietas, aversão a alimentos com alto valor energético, medidas compensatórias para o controle do peso como uso de diuréticos e laxantes, episódios de compulsão, práticas purgantes. Os episódios vão ocorrendo com mais frequência como efeito colateral das restrições alimentares conforme elas aumentam.

Somente o hábito de fazer dietas restritivas e frequentemente estar em restrição alimentar por si só já é uma característica dos transtornos alimentares. Práticas não saudáveis para controle de peso como comer em quantidades exageradamente pequenas, pular refeições, jejum, tomar remédios para emagrecer, substituir refeições por shakes e suplementos já caracterizam um "comer transtornado", de acordo com a Associação de Psiquiatria Americana e a Associação Dietética Americana (Leal et al., 2013). 
O padrão de beleza imposto pela sociedade, que difere muito da realidade da maioria dos indivíduos, faz com que eles se sintam desconfortáveis quanto a sua aparência e influenciados a seguir uma dieta para poder adequar-se ao padrão. A dieta, apresentada como solução, reverbera a ideia de que através dela será possível se encaixar nos padrões e, caso isso não ocorra, é porque a dieta não foi seguida corretamente, gerando na pessoa o sentimento de incapacidade e falta de autocontrole (Leal et al., 2013).

A interrupção da dieta é uma consequência inevitável e não reflete uma inadequação pessoal como a falta de autocontrole e disciplina. Isso não significa que a modificação do comportamento alimentar não seja necessária para alguns, em especial para aqueles que correm risco de comorbidades pelo excesso de peso e alimentação inadequada. Entretanto, a prática de dietas não pode ser banalizada e seguida indiscriminadamente, sem a devida orientação profissional (Soihet \& Silva, 2019).

\section{Suplementos e pílulas milagrosas}

A utilização de suplementos alimentares com a finalidade de obter melhorias na saúde e para fins estéticos vem aumentando a cada ano. A busca pela vida saudável gerou um aumento nas últimas décadas nas inscrições da população nos centros de treinamento e ginásios de musculação. Simultaneamente, ocorreu também a alta comercialização de suplementos alimentares com o intuito de melhorar o desempenho físico e estético dos indivíduos (Oliveira et al., 2018), entretanto muitos jovens e atletas utilizam sem a devida responsabilidade, fazem a auto prescrição ou são prescrições de amigos e não procuram o apoio de um profissional capacitado gerando diversos riscos para a saúde (Prado et al., 2018).

Os suplementos são produtos que devem estar sempre associados à boa alimentação, tendo em sua estruturação diversas vitaminas, minerais, produtos herbais, aminoácidos, enzimas e metabólitos. Esses produtos são encontrados em forma de cápsulas, pó, líquido, gel, cápsulas de gel e comprimidos. Seus principais objetivos são o aumento de massa muscular, a perda de peso corporal ou a melhora na performance esportiva (Nabuco et al., 2016).

Com o amplo crescimento dessa indústria no mercado brasileiro, uma gigante variedade de produtos se disseminou pelo ramo comercial suprindo a demanda existente entre os consumidores. Alguns exemplos dos suplementos mais vendidos na indústria brasileira são: Cafeína, Creatina, Whey protein e aminoácidos de cadeia ramificada (Bcaa).

O primeiro suplemento que será citado como exemplo será a famosa cafeína, que é classificada como um alcalóide do grupo das xantinas. Essa substância pode ser encontrada em plantas, chás, guaraná, erva-mate, cola, cacau e no café. Esse estimulante vem se tornando conhecido cada vez mais entre jovens e adultos praticantes de atividade física (Calfee \& Fadale, 2017). A dose

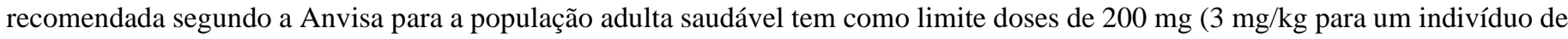
$70 \mathrm{~kg}$ ). Embora não se tenha afirmações concretas sobre o exato mecanismo e efeito ergogênico da cafeína, pressupõe-se que durante a atividade física ocorre o aumento da oxidação lipídica, que aumenta as taxas de ácidos graxos livres no sangue e/ou a queima de triglicerídeos intramusculares e com isso armazena os estoques de glicogênio muscular, fazendo com que o indivíduo pratique a atividade física de forma mais intensa (Goston, 2011). Portanto esse suplemento é bastante utilizado em treinamentos aeróbicos.

Já a creatina, um dos suplementos mais estudados nos últimos anos, é um aminoácido que pode ser encontrado em alguns alimentos e também pode ser produzido endogenamente. Ela é encontrada de forma livre (C) e fosforilada (CP) e 95\% desta substância é armazenada nos músculos esqueléticos. Pelo fato de não adquiri-la em quantidades significativas através de alguns alimentos como carne e peixe, atletas de diversas modalidades vêm utilizando a suplementação desse composto para melhorar o rendimento esportivo, pois, segundo Da Silva e colaboradores (2018) afirmam, contêm apenas $1 \mathrm{~g}$ de creatina para cada $250 \mathrm{~g}$ de carne crua, justificando a procura pelo suplemento desse suplemento. A principal fonte desse estudo está concentrada em atletas que praticam esportes de alta intensidade em um curto período de tempo, como por exemplo a musculação. 
Desde que a creatina começou a ser utilizada como suplementação, diversos protocolos foram desenvolvidos para a utilização desse produto, entre eles o protocolo da saturação, que consiste na ingestão de uma alta dosagem de creatina durante um período, realizada pelo consumidor para que a célula fique com excesso desse substrato, e dessa forma, o músculo conseguiria manter um estoque de creatina durante a fase de manutenção. Porém existem algumas evidências que essa fase de "carregamento" (5-7 dias com uma dosagem de 20-25 g/dia) da creatina não há a necessidade de ser feita pelo indivíduo, relatando que doses mais baixas (3-5 g/dia) são eficazes para aumentar os estoques de creatina intramuscular, promover hipertrofia e recuperação muscular. As dosagens recomendadas serão administradas de acordo com as atividades físicas realizadas e da individualidade de cada paciente (Mills et al., 2020).

O terceiro exemplo de suplemento mais vendido na indústria brasileira nesse artigo é o "whey protein". Essa proteína pode ser extraída do soro do leite e sua estrutura é composta por proteínas de alto valor biológico e altas concentrações de BCAA (exclusivamente Leucina, Isoleucina e Valina). Esse suplemento alimentar serve para complementar as refeições diárias do indivíduo. É bastante utilizado pelos atletas para alcançar as doses diárias de proteína e é considerado um dos maiores aliados para o ganho de massa livre de gordura. As doses recomendadas desse produto são em média entre 20 a $30 \mathrm{~g} /$ dia. Entretanto, segundo os autores (Santos, 2011 \& Sussmann, 2013), no Brasil o uso indiscriminado de suplementos tem sido evidente nos indivíduos que o consomem, em específico do tipo "whey protein “. Normalmente essa proteína é vendida nos mercados e não só melhoram a performance como também servem como alérgenos.

O Bcaa, último suplemento citado como exemplo, foi um assunto bem polêmico nos últimos anos dentro da comunidade científica. Ele possui em sua composição uma maior concentração de leucina seguida de valina e isoleucina. Muitos autores citam esses suplementos de cadeia ramificada vendido no comércio como irrisório, pois é vendido por um preço bastante elevado e seus compostos estão presentes no whey protein que é considerado um suplemento mais completo. Esse produto é comercializado com o intuito de estimular a síntese proteica quando associado a uma atividade física e recuperação muscular pós exercício, porém as evidências mostram que a eficácia da ingestão isolada do Bcaa para hipertrofia muscular são ilusórias. Segundo os estudos de Carina et al. (2019), o uso desse suplemento não apresenta nenhum efeito significativo na síntese proteica e o estudo realizado por Trisha et al. (2018) mostra que o produto não demonstrou eficácia na recuperação muscular posteriormente ao treino.

Muitas das vezes esses produtos citados são comercializados como uma forma mais rápida de obter rendimento nas atividades físicas de forma milagrosa por vendedores que só pensam em lucrar em cima dos produtos e esquecem que podem acabar prejudicando a saúde dos consumidores. Algumas substâncias podem até melhorar a capacidade atlética de indivíduos saudáveis, mas outras são consideradas uma promessa falsa (Silva et al., 2020).

\section{Impactos das dietas restritivas}

A alimentação é uma necessidade fundamental do ser humano. $\mathrm{O}$ ato de se alimentar representa um momento de interação social, familiar, muitas vezes carregado de simbolismos, relações com à saúde, transcendendo o valor nutritivo e as características organolépticas do alimento, possuindo motivações ocultas relacionadas às carências psicológicas e às vivências emotivas independente da alimentação.

Porém, com a busca pelo corpo perfeito idealizado pela sociedade atual, a aderência a dietas restritivas amplamente veiculadas pela mídia vem crescendo exponencialmente, e expondo os pacientes que as seguem aos seus riscos e malefícios apresentando efeito rebote a longo prazo, tendendo a ganhar mais peso do que quando não estavam em restrição calórica, o que leva à insatisfação corporal, transtornos alimentares e infelicidade (Soihet \& Silva, 2019).

Essas dietas vêm sendo associadas ao crescente aumento do risco para transtornos alimentares e outros efeitos psicológicos, como aumento da depressão e da ansiedade. (Montani \& Schutz \& Dulloo, 2015). Os estudos de McFarlane et al. (1999) apontaram 
que a adesão a dietas restritivas influencia o comportamento alimentar, gerando frustrações, compulsão e culpa, direcionando as pessoas a terem efeitos psicológicos negativos na autoestima, cognição, felicidade e afeto.

De acordo com os estudos de Sousa e Sanches (2018), o aumento da incidência da anorexia nervosa nas últimas décadas seria explicado devido às pressões sociais cada vez maiores para que as mulheres tenham um corpo esbelto, em especial quando atuam em meninas jovens, em uma idade em que elas são mais vulneráveis, ou quando elas têm ocupações em áreas em que a forma e o tamanho do corpo são enfatizados, como modelos ou nutricionistas.

Efeitos negativos na autoestima, além da insatisfação com a imagem corporal são fatores precursores de transtornos alimentares em função da distorção cognitiva da percepção da autoimagem, que é enfraquecida por constantes práticas inadequadas de controle de peso, adesão a dietas da moda e comportamentos alimentares desregulados (Andrade \& Bosi, 2003).

O público feminino, especialmente o mais jovem, é o que tem maior propensão a aderir às dietas da moda. De acordo com Wolf (1996), Ogden (1996) e Malysse (1998), o embelezamento feminino tende a ser direcionado para o corpo e esse cuidado muitas vezes chega a ser obsessivo e patológico. O estudo desenvolvido por Souto e Ferro-Bucher (2006) afirma que são perceptíveis os danos à saúde da adesão indiscriminada a dietas restritivas, que a mídia influencia adolescentes na insaciável e desesperada busca pelo corpo perfeito que é associado ao sucesso. A indústria das dietas não prioriza a saúde como deveria, mas sim o capital, dessa maneira informações enviesadas no intuito de favorecer essa indústria chegam até os indivíduos que buscam emagrecer, influenciando o psiquismo dos mesmos.

De acordo com o estudo de Betoni et al. (2010), onde foram coletados dados de 40 pacientes por meio de um questionário, 29 pacientes afirmaram nunca ter realizado anteriormente dietas da moda e 11 afirmaram já ter aderido a esse tipo de dieta. Quando questionados acerca de patologias anteriores dos pacientes que afirmam nunca ter praticado dietas da moda, 41,4\% relataram não apresentar nenhuma doença, 37,9\% declararam hipertensão arterial sistêmica, 3,4\% diabetes mellitus, 31,1\% dislipidemias e 24,1\% doenças que não são relacionadas ao questionário como desvio e desgaste de coluna, hipotireodismo, insuficiência venosa, e artrite. Em relação aos pacientes que declararam ter realizado dietas da moda 81,81\% relataram não apresentar nenhuma doença, 9,09\% relatou hipertensão arterial sistêmica, 9,09\% diabetes mellitus, 9,09\% dislipidemia e 9,09\% possuía outra doença não relacionada no questionário.

Field et al. (1999) realizaram um estudo de coorte prospectivo a partir de 6.982 mulheres com idade entre 9 e 14 anos, durante um ano, onde foi constatado que a grande mídia tem parcela da responsabilidade da criação de padrões estéticos irreais para jovens e adolescentes, pois, de acordo com a comunidade médica, o ideal de peso estabelecido pelos veículos midiáticos é extremamente baixo. Influencers e celebridades muitas vezes demonstram magreza extrema, o que pode ter contribuição no aumento do risco de desenvolvimento de comportamentos de aspecto bulímico, como o consumo de laxantes e a prática purgante. O mesmo estudo demonstrou que a influência de figuras públicas extremamente magras nas mídias foi um fator que levou de 30\% a $40 \%$ das mulheres entrevistadas a prática de vômitos e uso indiscriminado de laxantes.

O estudo de coorte de Patton et al. (1999) feito com estudantes entre 14 e 15 anos de idade de escolas de Victoria na Austrália concluiu que uma dieta restritiva é o principal fator para o desenvolvimento de transtornos alimentares. No estudo também pode se observar que entre as estudantes do sexo feminino, o risco de desenvolvimento de transtornos alimentares nos seis meses seguintes a adesão a uma dieta é 18 vezes maior nas estudantes que seguiram dietas restritivas do que nas que não seguiram dieta alguma.

Com o intuito de uma perda rápida de peso e a obtenção de um corpo mais magro, as dietas detox ganharam muito espaço, pois trazem essa promessa junto com a de eliminação das toxinas que estão causando dano ao seu organismo. De acordo com o estudo de Freire e Araújo (2017) em que foi analisada a composição nutricional de dietas detox publicadas em revistas não científicas, tanto os valores de lipídios quanto de carboidratos foram considerados abaixo do adequado em maior parte das dietas analisadas. 
Dietas pobres em carboidratos têm efeitos negativos no sentimento de saciedade e induzem menor liberação e circulação da insulina no sangue, dietas hipolipídicas prejudicam a absorção de vitaminas lipossolúveis. No mesmo estudo, foi observado nas dietas analisadas que o conteúdo de fibras era excessivo nas dietas, e os valores de ferro e cálcio eram abaixo do necessário.

Baseado no artigo de Soihet e Silva (2019), cada vez mais estudos vêm comprovando a associação de dietas e restrições alimentares com ganho de peso futuro e obesidade. O ciclamento de peso, conhecido como efeito sanfona, ocasionado por frequentes variações na composição corporal, é um processo que traz como consequência o aumento de comorbidades.

Como traz o estudo de Steen et al., (1998) que foi feito com jovens lutadores e calculou o Gasto Energético Basal (GEB) dos adolescentes, nos indivíduos que variaram mais de peso ao longo da vida, o Gasto Energético Basal era 14\% menor, o que sugere que a frequente e descontrolada adesão a dietas restritivas traria prejuízo para a função do metabolismo. Alguns estudos trazem a confirmação de que a vontade de comer durante um período de restrição alimentar gera uma compensação onde o indivíduo come exageradamente quando o acesso ao alimento é permitido novamente, pois ocorre um aumento anormal do apetite que leva à uma ingestão alimentar excessiva. Ao mesmo tempo que quando se finaliza um período de restrição calórica ocorre a utilização dos lipídios antes deixados de lado pelo metabolismo, auxiliando no reganho de peso e causando o famigerado efeito sanfona. (Soihet \& Silva, 2019)

Além das consequências físicas da restrição alimentar, podem ser desencadeadas diversas reações psicológicas negativas com a adesão a dietas restritivas. Intervenções com mais restrições alimentares vêm sendo associadas a um frequente aumento da depressão, ansiedade, nervosismo, fraqueza e irritabilidade, enquanto intervenções dietéticas menos restritivas corroboram com o aumento do bem-estar e da autoestima, diminuição do estresse e aumento da autonomia. (Soihet \& Silva, 2019)

Em um estudo realizado com adolesecentes do sexo feminino onde foi analisada a relação entre restrição dietética e insatisfação com o corpo foi observado que dietas restritivas e insatisfação corporal são intrinsecamente relacionados e que pessoas com maiores níveis de restrição alimentar possuem maiores probabilidades de desenvolverem depressão, problemas de autoestima e transtornos alimentares. (Jonhson \& Wardle, 2015).

\section{Considerações Finais}

O estudo abrangeu uma pesquisa sobre dietas restritivas, buscando seus diversos tipos como detox, dieta cetogênica, dieta low carb, dieta mediterrânea, dieta Dukan, entre outras. Além das dietas da moda, foram pesquisadas quais os seus impactos na nutrição comportamental.

A incessante busca pelo corpo perfeito estimulada pela sociedade e pela mídia motiva os indivíduos a uma permanente insatisfação corporal levando-as a aderir dietas da moda altamente restritivas no intuito de se enquadrar nesses padrões impostos e acreditar que essas dietas trarão felicidade e beleza. Apesar dessas dietas apresentarem algum resultado a curto prazo, a longo prazo os indivíduos que aderem essas dietas tendem a entrar em efeito rebote, ganhando mais peso do que perderam com a dieta, o que traz insatisfação com o corpo, transtornos alimentares e depressão.

Os principais meios em que se encontram esses planejamentos alimentares restritivos são em revistas voltadas para o público que busca uma transformação corporal, websites, aplicativos, anúncios publicitários e por pessoas influentes nas redes sociais, que não apresentam um conhecimento profissional sobre o assunto, e, assim, tendem a influenciar o público a realizar essas dietas para alcançar em pouco tempo o corpo desejado.

A restrição alimentar traz como consequências diversos prejuízos à saúde física e mental. O vai e vem entre dietas das modas modifica o comportamento alimentar sendo um combustível propulsor para transtornos alimentares e dificuldades na relação com a alimentação. A distorção da autoimagem corporal é um problema principalmente em mulheres jovens, causada por padrões 
estéticos incompatíveis com a realidade, favorecendo a adesão a planos alimentares sem nenhuma individualização e adequação às necessidades da paciente, gerando insatisfação e comorbidades.

Destarte, é fulcral a orientação de um nutricionista ao se iniciar um plano dietético para auxiliar na obtenção de melhores resultados, na prevenção de doenças e melhora da qualidade de vida de forma mais efetiva. O nutricionista é o profissional responsável pela função de garantir uma ingestão alimentar coerente com as necessidades nutricionais do paciente, fornecendo orientações adequadas sobre os alimentos a serem ingeridos na dieta e monitorando sua composição corporal. Porém, falta consciência e valorização por parte da população, em relação a importância e função da orientação adequada de um profissional nutricionista na prevenção de doenças e na busca de uma qualidade de vida melhor. É primordial também que as pessoas saibam que o seu plano alimentar é exclusivo e não deve ser compartilhado com as outras, pois possuem estilos de vida e organismos diferentes.

Devido isso, sugere-se que se façam novos estudos dentro do escopo da pesquisa para esclarecer a relação entre a incorreta adesão a dietas da moda a suplementos com os transtornos do âmbito do comportamento alimentar e com o comportamento nutricional.

\section{Referências}

Alvarenga, M. \& Figueiredo, M. \& Timerman, F. \& Antonaccio, C. (2015). Nutrição Comportamental. Ebook.

Amaral, A. \& Nascimento, O. (2020). Efeitos da suplementação de creatina sobre o desempenho humano: Uma revisão de literatura. BIUS, 21(15).

Andrade, A \& Bosi, M. L. M. (2003). Mídia e subjetividade: impacto no comportamento alimentar feminino. Revista de Nutrição, $16(1)$, 117-125.

Andrade, C. et al. (2021) Dietas restritivas e o risco para o desenvolvimento de compulsão alimentar em adolescentes. Brazilian Journal of Development, 7(5), 50918-50928.

Antonio, J. et al. (2021). Common questions and misconceptions about creatine supplementation: What does the scientific evidence really show? Journal of the International Society of Sports Nutrition, 18(13).

Betoni, F. et al. (2010). Avaliação de utilização de dietas da moda por pacientes de um ambulatório de especialidades em nutrição e suas implicações no metabolismo. ConScientiae Saúde, 9(3), 430-440.

Brasil. Ministério da Saúde. Guia alimentar para a população brasileira. 1-159.

Bokhorst, V. S. (2005). Nutritional support strategies for malnourished cancer patients. Eur J Oncol Nurs, 2, 74-83.

CFN - Conselho Federal de Nutricionistas. (2018). Resolução CFN Nº 599/2018. Código de Ética e de Conduta do Nutricionista.

Cormier, B. (2018). Exposure to fad diet advertising among youth and young adults in Canada. Tese (Doutorado) - University Of Waterloo, Canadá.

Ferreira, F. A. \& Vanni, A. C. \& Spinelli, R. B. \& Santolin, M. B. (2018) Utilização de diferentes estratégias nutricionais por praticantes de musculação em uma academia na região norte do Rio Grande do Sul. Revista Brasileira de Nutrição Esportiva, 12(75), 936-943.

Fraga, T. B. et al. Uso de Estratégias de Comunicação e Informação por Nutricionistas no Instagram: uma análise sob a interpretação do Código de Ética e de Conduta do Nutricionista. Trabalho de conclusão de curso (TCC) na Nutrição.

Field, A. E. et al. (1999). Relation of peer and media influences to the development of purging behaviors among preadolescent and adolescent girls. Arch Pediatr Adolesc Méd. 153(11), 1184-1189.

Freire, A. C. S. A. \& Araújo, L. B. (2017). Composição nutricional de dietas de detoxificação divulgadas em revistas e em mídia digital não científicas. RBNE Revista Brasileira de Nutrição Esportiva, 11, (65), 536-543.

Johnson, F. \& Wardle, J. (2005). Dietary Restraint, Body Dissatisfaction, and Psychological Distress: A Prospective Analysis. Journal of Abnormal Psychology, 114(1), 119-125.

Khawandanah, J. \& Tewfik, I. (2016). Fad Diets: Lifestyle Promises and Health Challenges. Journal of Food Research, 5(6), 80-94.

Leal, G. et al. (2013). O que é comportamento de risco para transtornos alimentares em adolescentes? J. bras. psiquiatr, 62(1), 62-75.

Lima, A. V. et al. (2015). Teor calórico e de macronutrientes de dietas veiculadas em revistas femininas não científicas impressas. Revista. Interdisciplinar, 8(4), $136-143$.

Lima, C. A. et al. (2017). Efeito da Cafeína sobre o Desempenho em Teste de Capacidade Aeróbica. Revista Brasileira de Nutrição Esportiva, 11(67), 884-890. 
Lira, A. et al. (2017) Uso de redes sociais, influência da mídia e insatisfação com a imagem corporal de adolescentes brasileiras. Jornal Brasileiro de Psiquiatria [online], 66(3), 164-171.

Longo, E. N. \& Navarro, E.T. (2010). Avaliação de utilização de dietas da moda por pacientes de um ambulatório de especialidades em nutrição e suas implicações no metabolismo. ConScientiae Saúde, 9(3), 430-440.

Macedo, M. et al. (2021). Os riscos para saúde associados ao consumo de suplemento alimentar sem orientação nutricional. Research, Society and Development. $10(3)$.

Magalhães, L. et al. (2017). A influência de blogueiras fitness no consumo alimentar da população. Revista Brasileira de Obesidade, Nutrição e Emagrecimento. 11(68), 685-692.

Magalhães, V. C. \& Mendonça, G. (2005). Transtornos alimentares em universitárias: estudo de confiabilidade da versão brasileira de questionários auto preenchiveis. Revista Brasileira de Epidemiologia [online]. 8(3), 236-245.

Maltez, Bárbara. A influência de dietas restritivas nos diversos transtornos alimentares em mulheres jovens. Trabalho de conclusão de curso (TCC) na Nutrição.

Malysse, S. (1998). Em busca do corpo ideal. Sexualidade, Gênero e Sociedade. 7(8), 12-17, 1998.

Marangoni, J. S. \& Maniglia, F. P. (2017). Análise da composição nutricional de dietas da moda publicadas em revistas femininas. Revista da Associação Brasileira de Nutrição - RASBRAN, 8(1), 31-36.

Mcfarlane, T. \& Polivy, J. \& Mccabe, R. E. (1999). Help, not harm: Psychological Foundation for a Nondieting Approach Toward Health. Journal Of Social Issues. 55( 2), 261-276.

Montani, J. P. \& Schutz, Y. \& Dulloo, A. G. (2015). Dieting and weight cycling as risk factors for cardiometabolic diseases: who is really at risk? Obesity Reviews. 16, 7-18.

Morgan, C. M. \& Vecchiatti, I. R. \& Negrão, A. B. (2002). Etiologia dos transtornos alimentares: aspectos biológicos, psicológicos e sócio-culturais. Brazilian Journal of Psychiatry [online]. 24(3), 18-23.

Nogueira, L. R. \& Mello, A. V. \& Spinelli, M. G. N. \& Morimoto, J. M. (2016). Dietas da moda consumidas por desportistas de um clube e academias em São Paulo. RBNE - Revista Brasileira de Nutrição Esportiva. 10(59), 554-561.

Ogden, J. (1996). A vez do gordo? Desfazendo o mito da dieta.

Pacheco, C. Q. \& Oliveira, M. \& Stracieri, A. (2009). Análise nutricional de dietas publicadas em revistas não científicas destinadas ao público feminino. NUTRIR GERAIS - Revista Digital de Nutrição. 3(4), 346-361.

Passos, J. A. \& Vasconcellos-Silva, P. B. \& Santos, L. A. S. (2020). Ciclos de atenção a dietas da moda e tendências de busca na internet pelo Google trends. Ciênc. saúde coletiva. 25(7), 2615-2631.

Patton, G.C \& Selzer, R \& Coffey, C \& Carlin, J B \& Wolfe, R. (1999). Onset of adolescent eating disorders: population based cohort study over 3 years. BMJ. $318,765-768$

Peixoto, S. F. F. (2020). Redes Sociais e Escolhas Alimentares Social Networks and Food Choices. Faculdade de Ciências da Nutrição e Alimentação da Universidade do Porto.

Penz, L. et al. (2008). Risco para desenvolvimento de transtornos alimentares em estudantes de Nutrição. Scientia Medica. 18(3), $124-128$.

Santos, C. S. \& Nascimento, F. E. (2019). Consumo isolado de aminoácidos de cadeia ramificada e síntese de proteína muscular em humanos: uma revisão bioquímica. Einstein. 17(3), 48-98.

Soihet, J. \& Silva, A. D. (2019). Efeitos psicológicos e metabólicos da restrição alimentar no transtorno de compulsão alimentar. Nutrição Brasil. 18(1), 55.

Sousa, L. \& Sanches, R. (2018). O corpo do/no discurso midiático das dietas: efeitos do novo e da novidade. Revista Famecos Porto Alegre. 25(1).

Souto, S. \& Ferro-Bucher, J. (2006). Práticas indiscriminadas de dietas de emagrecimento e o desenvolvimento de transtornos alimentares. Rev. Nutr. 19(6), 693-704.

Steen, S. et al. (1988). Metabolic Effects of Repeated Weight Loss and Regain in Adolescent Wrestlers. JAMA. 260, 47-50.

Teixeira, V. \& Matos, B. (2020). O efeito da suplementação de cafeína no exercício aeróbio. Trabalho de conclusão de Curso na Nutrição.

Vandusseldorp, T. A. \& Escobar, K. A. \& Jhonson, K. E. \& Stratton, M.T. (2018). Efeito da suplementação de aminoácidos de cadeia ramificada na recuperação após exercício excêntrico agudo. Nutrients. 10, 1389.

Viana, D. S. O. (2015). Análise Nutricional das Dietas da Moda. Trabalho de Conclusão de Curso na Nutrição.

Wolf, N. (1996). O mito da beleza: como as imagens de beleza são usadas contra as mulheres. 